\title{
Pesquisa empírica em Comunicação Organiza- cional e Relações Públicas: proposta metodológica e olhar sobre a prática de assessorias de Comunicação em Goiás
}

\author{
Simone Antoniaci Tuzzo* \\ Tiago Mainieri***
}

\section{Resumo}

A proposta do artigo é apresentar e discutir uma pesquisa empírica em Comunicação Organizacional e Relações Públicas. Ao destacarmos os resultados da pesquisa empírica, propõe-se também discutir alguns de seus aspectos metodológicos. Partindo do princípio que as pesquisas empíricas nem sempre trazem a devida explicitação metodológica, temos um prejuízo no avanço e na consolidação das pesquisas de campo. Nesse sentido, analisamos os resultados e o percurso da pesquisa empírica sobre as assessorias de Comunicação de organizações do Estado de Goiás. Mais que isso, o próprio resultado da pesquisa também se caracteriza como objeto de estudo, ao passo que reafirma a importância dos Relaçóes Públicas na atuação em Assessorias de Comunicação.

Palavras-chave: Assessorias de Comunicação. Pesquisa Empírica em Comunicação. Relações Públicas.

\section{Empirical research in Organizational Communication and Public Relations: a methodological proposal and a look at communication departments in Goiás State} Abstract

This paper has a purpose to present and discuss an empirical research in organizational communication and public relations. When we emphasize the empirical

\footnotetext{
* Doutora em Comunicação pela Universidade Federal do Rio de Janeiro (UFRJ) e professora adjunta do Programa de Mestrado em Comunicação e do curso de Relações Públicas, Faculdade de Comunicação e Biblioteconomia da Universidade Federal de Goiás (UFG). Autora do livro Deslumbramento Coletivo: Opinião Pública, Mídia e Universidade. Goiânia-GO, Brasil. E-mail: simonetuzzo@hotmail.com ** Doutor em Ciências da Comunicação pela Universidade de São Paulo (USP) e professor adjunto no Curso de Relações Públicas e no Mestrado em Comunicação, Faculdade de Comunicação e Biblioteconomia da Universidade Federal de Goiás (UFG). Goiânia-GO, Brasil. E-mail: tiagomainieri@hotmail.com
} 
research results, we also discuss some of their methodological aspects. As the empirical researches don't always bring the correct methodological evidences, we can have some losses as in the advancement as in the researches consolidation. So, we have analyzed the development and the results of empirical researches in the communication departments in some organizations of Goiás state. Besides, the research result can be considerate as the study object, and also giving to the publics relations their real importance in the communication departments.

Key words: Organizational Communication. Empirical Research. Social Organizations.

\section{Investigación Empírica en Comunicación Organizacional y Relaciones Públicas: propuesta metodológica y un enfoque aplicado sobre la práctica en las Asesorías de Comunicación en Goiás, en Brasil}

\section{Resumen}

La propuesta de este artículo es presentar y discutir una investigación empírica en Comunicación Organizacional y Relaciones Públicas. Hemos destacado los resultados de la investigación empírica, proponiendo también discutir algunos de sus aspectos metodológicos. Partiendo del principio de que las investigaciones empíricas ni siempre traen la debida explicación metodológica, tenemos una pierda en el avance y en la consolidación de las investigaciones de campo. En este sentido, hemos analizado los resultados y el recorrido de la investigación empírica sobre las asesorías de comunicación en las organizaciones de Goiás, en Brasil. Más que eso, el propio resultado de la investigación también se caracteriza como objeto de estudio, al paso que reafirma la importancia de la actuación de los Relaciones Públicas en las Asesorías de Comunicación.

Palabras clave: Asesorías de Comunicación. Investigación Empírica en Comunicación. Relaciones Públicas.

\section{Introdução}

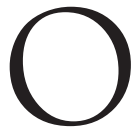

artigo propõe a apresentação e análise de uma pesquisa empírica no campo das Relações Públicas e da Comunicação Organizacional. Constitui-se objeto de estudo deste artigo, tanto as assessorias de Comunicação de organizações do Estado de Goiás - para compreendermos o seu funcionamento - quanto, a própria metodologia de busca desses dados. Dessa forma, pretende-se destacar a importância da pesquisa empírica nas Ciências da Comunicação.

As pesquisas empíricas se transformam em uma comprovação ou em questionamento de teorias e reflexões levantadas na Uni- 
versidade, ao passo que os seus resultados também se configuram como novos objetos de estudo e reflexão.

O cotidiano se caracteriza como um grande laboratório, no qual todo tipo de manifestação possa ser analisado, sob a ótica da ciência que se pesquisa e que se quer descobrir. $\mathrm{O}$ olhar crítico e o questionamento se sobrepõem ao senso comum. No caso da Comunicação, revistas, jornais impressos, internet, rádio, televisão e as organizações se constituem em material permanente de estudo. Os investigadores deixam de ser influenciados pela grande massa, sendo levados a um novo questionamento.

Essa reflexão nos dá a certeza de que a teoria e a prática não são processos dissociados, pelo contrário, uma não pode se completar sem a outra. Podemos nos firmar no princípio que na sociedade moderna a comunidade se transforma no próprio laboratório permanente de pesquisa e observação. Nesta lógica, o tripé ensino - pesquisa - extensão tem função conjugada e permitirá reconhecer que o espaço universitário dedicado à construção do conhecimento está em toda a sociedade.

Neste formato, as pesquisas empíricas contribuem para o conhecimento da sociedade frente aos conceitos de Comunicação, capazes de transformar as teorias científicas em verdadeiros conceitos aplicados.

A pesquisa empírica se coloca como uma questão central no desenvolvimento das novas interações da Comunicação social. A questão comunicacional, para além de seu espaço próprio, interessa a todas as demais atividades humanas. A ciência, em seus múltiplos aspectos, investe-se de uma competência para tratar de todas as coisas do mundo físico ou social - segundo as perspectivas de seus próprios objetivos e processos. O importante é observar a área de interface entre a Comunicação e as demais áreas de conhecimento humano.

Este trabalho apresenta uma pesquisa realizada com sete assessorias de Comunicação no Estado de Goiás, de organizações públicas e privadas, dos primeiro, segundo e terceiro setores, atuantes em diversas áreas, tais como, esporte e hotelaria. Para a coleta dos dados foi criado um roteiro semiestruturado de entrevistas aplicado a vários funcionários dos departamentos de Comunicação, com o objetivo de conhecer e analisar as organi- 
zações. O roteiro foi composto por 12 itens que serviram de base para a entrevista dos pesquisadores.

A realidade encontrada a partir desse trabalho reforça a ideia da importância da pesquisa empírica para reafirmar os estudos teóricos desenvolvidos nas Universidades. Além disso, a pesquisa empírica não tem somente um caráter de reforço do discurso de sala de aula, mas, ela mesma é fonte de transformação de discursos teóricos que estão constantemente em ajustes, reformas e aplicação, para que o mundo da academia e o mundo do trabalho estejam cada vez mais próximos.

\section{A pesquisa empírica sobre as assessorias de Comunicação em Goiás - um olhar reflexivo}

A pesquisa empírica em Comunicação Organizacional e Relações Públicas tem se revelado como um campo fértil em termos de procedimentos metodológicos. A inserção dessa área no âmbito das Ciências da Comunicação tem se caracterizado pela natureza interdisciplinar desses estudos. Em especial, uma perspectiva em termos de procedimentos e metodologias qualitativas vem marcando tais pesquisas. Este trabalho propõe analisar esse percurso da pesquisa empírica a partir de uma investigação conduzida com organizações do Centro-Oeste.

O fenômeno da Comunicação no contexto das organizações revela uma vertente de estudos teóricos e práticos, que estão envoltos em um objeto que permite um olhar multifacetado, com leituras e interpretações distintas. Esse objeto ainda paira sob a Comunicação como algo novo, distinto de outras vertentes nas Ciências da Comunicação que tradicionalmente constituíram-se como linhas de pesquisa.

O campo da Comunicação abarca subáreas que contemplam seus diferentes processos e práticas. Faz-se necessário reconhecer os diferentes percursos teóricos e metodológicos para entender o "comunicacional" no contexto organizacional.

Neste sentido, corrobora a afirmação de Braga (2001, p.18) acerca dessa perspectiva. Para o autor, "todo e qualquer fato humano seria problematizável no ângulo comunicacional, o que significa 
objetivar, destacar e problematizar a dimensão comunicativa dos diversos procedimentos humanos".

A importância dos processos mediáticos nos estudos do campo da Comunicação, ainda de acordo com Braga (2001), não pode restringir a perspectiva ampla sobre o comunicacional. $\mathrm{O}$ autor coloca como desafio ao campo desentranhar o objeto da Comunicação dos demais objetos de conhecimento humano e social. Uma das questões nucleares das pesquisas em Relações Públicas e Comunicação Organizacional tem sido tentar delimitar esses campos, estabelecendo limites e interfaces. Tarefa que vem sendo cumprida pelos pesquisadores reunidos em núcleos e grupos de pesquisa vinculados, por exemplo, a Sociedade Brasileira de Estudos Interdisciplinares da Comunicação - Intercom e Associação Brasileira de Pesquisadores de Comunicação Organizacional e Relações Públicas - Abrapcorp. Além do esforço coletivo em torno da produção bibliográfica nessa área, que nos últimos anos tem demonstrado vigor.

A oportunidade de inserirmos uma discussão metodológica acerca da produção científica nesse campo é vital e se constitui num espaço para reflexão dessas práticas teóricas. Cabe destacar que a concepção metodológica muitas vezes restringe-se aos procedimentos técnicos de uma pesquisa empírica. Lopes (2003) defende a necessidade de um modelo metodológico para a Comunicação, considerando as condições concretas da prática científica em Comunicação.

$\mathrm{O}$ modelo proposto pela autora parte da premissa de que a pesquisa se configura como estrutura e como processo. Enquanto estrutura, temos uma articulação entre as instâncias epistemológica, teórica, metódica e técnica. Enquanto processo, temos a articulação entre as fases da pesquisa: definição do objeto, observação, descrição e interpretação. Da articulação entre estrutura e processo é que se constrói a prática da pesquisa empírica.

A autora sugere a aplicação do modelo metodológico tanto a discursos já produzidos quanto a discursos em produção. Portanto, trata-se de um modelo de interpretação metodológica caracterizando-se "como um modelo de reconstrução metodológica, isto é, um modelo para o intérprete/leitor; [...] e como um modelo de construção metodológica, um modelo para o investigador" (LOPES, 2003,p.115). 
A proposição vem preencher uma lacuna nas investigações em Comunicação, na medida em que permite uma análise da falta de explicitação da estratégia metodológica na grande maioria das dissertações e teses da área. Como afirma a autora (2003, p.101),

[...] é importante salientar que essas opções são normalmente tomadas com um baixo grau de consciência por parte do investigador. No caso das pesquisas de Comunicação Social, esse fato se expressa, em princípio, por uma quase ausência de explicitação da estratégia metodológica que sustenta a investigação.

O modelo metodológico se propõe a ser um modelo de construção do discurso científico e análise dos discursos produzidos. Nesse caso, temos duas funções primordiais: descritiva e crítica.

Por meio da descrição, que nunca é neutra, pois parte de uma série de postulados sobre a natureza da pesquisa, o modelo realiza a explicação dos fundamentos metodológicos da pesquisa. Mediante a função crítica, busca uma intervenção e reorientação das estratégias de investigação, na medida em que os obstáculos são identificados no processo de pesquisa e vias de superação podem ser propostas (LOPES, 2003, p.15).

Na figura 1, pode-se visualizar a representação gráfica do modelo metodológico da autora.

A análise da pesquisa com as assessorias de Comunicação em Goiás, a partir do modelo metodológico, nos permite extrapolar a mera descrição, remetendo-nos a uma leitura crítica, pois nos permite perceber problemas internos com relação à produção do conhecimento no campo da Comunicação e, além disso, nos permite conviccionar que o discurso e a prática científica devem estar embasados metodologicamente. Portanto, nossa intenção é delinear a 'arquitetura' da pesquisa, a partir da percepção de suas opções, seleções, combinações etc.

É com base no modelo metodológico de pesquisa desenvolvido por Lopes que iremos analisar alguns aspectos da pesquisa. $\mathrm{O}$ modelo concebe o processo de pesquisa enquanto articulação e "cruzamentos que se dão entre as operações envolvidas em cada fase e as operações propriamente estruturais dos níveis epistemológico, teórico, metódico e técnico" (2003, p.135). 
Figura 1 - Modelo metodológico da pesquisa proposto por Lopes (2003)

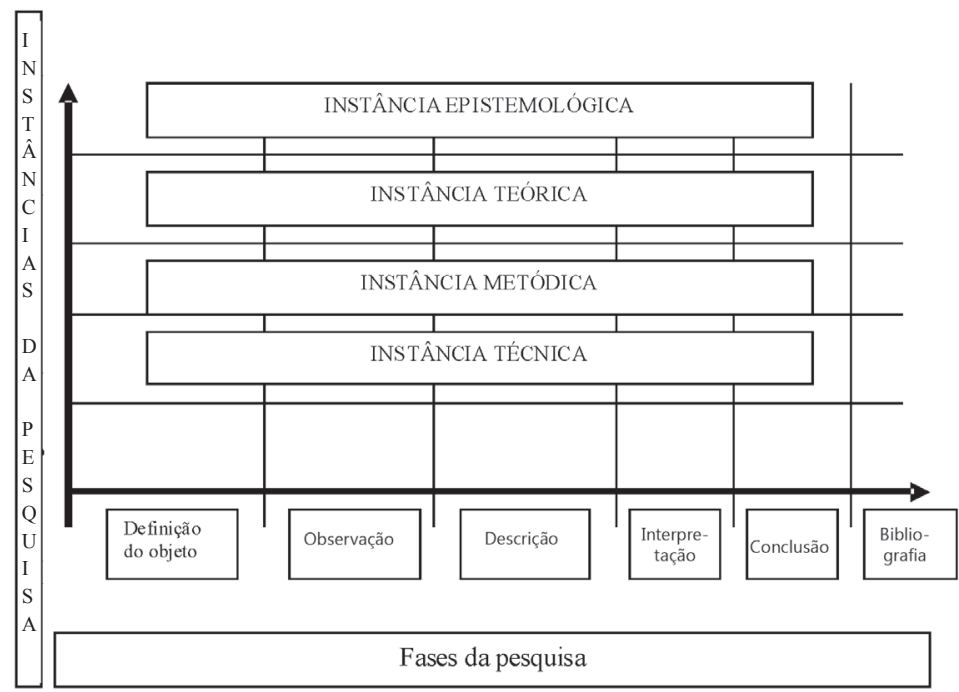

Fonte: (LOPES, 2003, p.156)

Como expusemos acima, a análise da pesquisa sobre as assessorias de Comunicação é fundamental para entendermos o processo de como se dá a pesquisa em Ciências Sociais, especialmente em Comunicação Organizacional e Relações Públicas. Esse exercício de reflexão metodológica nos permite, na verdade, uma reflexão sobre o campo em si, e como tem se dado o processo interno de produção dos discursos científicos, essencial para que a pesquisa no campo da Comunicação não seja reduzida somente a procedimentos de pesquisa.

O modelo apresenta a articulação vertical da estrutura da pesquisa e a articulação horizontal da pesquisa enquanto processo. Portanto, o modelo se configura numa dinâmica "rede de articulações verticais e horizontais tecida pelo raciocínio científico." (LOPES, 2003, p.96)

É a partir dessas articulações, imbricações e interconexões que concebemos a presente análise. Dessa forma, não partimos de uma visão estreita que burocratiza a pesquisa e a reduz a procedimentos, pelo contrário, conforme Lopes (2003, p.98) “[...] a complexidade 
do objeto das Ciências Sociais exige interpenetrações de suas diversas instâncias e voltas constantes entre as operações envolvidas em suas fases" (ver figura 2).

Figura 2 - Relação entre as instâncias e fases da pesquisa

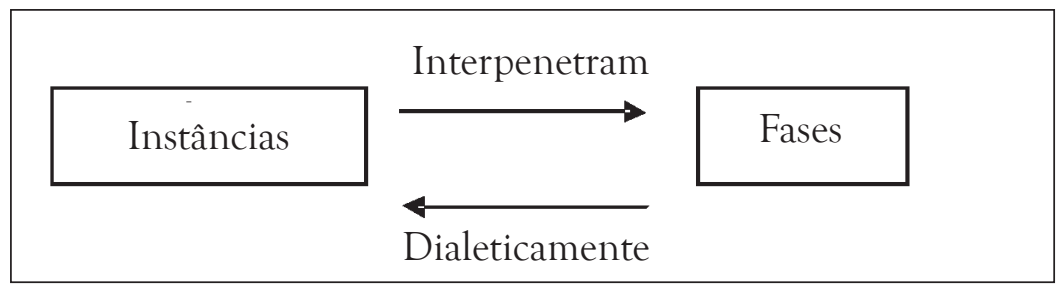

Martino (2001, p.73) afirma que a pesquisa empírica, além de fornecer dados que alimentam a reflexão, regula o trabalho reflexivo acerca do objeto. Para ele "o que se torna objeto de estudo da disciplina Comunicação são as práticas comunicacionais liberadas pela sociedade complexa.”

A pesquisa empírica em Comunicação caracteriza-se pela utilização de uma grande variedade de métodos, dentre eles o quantitativo destaca-se. (DA VIÁ; DENCKER, 2001). Apesar do forte apelo das pesquisas quantitativas, esforços têm sido empreendidos na consolidação de uma metodologia qualitativa. Este estudo sobre as assessorias de Comunicação de organizações goianas utiliza-se de uma abordagem qualitativa.

Da Viá e Dencker (2001, p.49) definem metodologia como:

O estudo analítico e crítico dos métodos de investigação e de prova. A metodologia não é, senão, uma reflexão, sobre a atividade científica que está sendo desenvolvida para obter, em determinado momento, um retrato dessa atividade - retrato esse que deferirá de acordo com a ciência sobre a qual estamos refletindo.

As pesquisas empíricas em Comunicação Organizacional e Relações Públicas exploram, descrevem, explicam e formulam predições sobre os acontecimentos do mundo que nos rodeia. Suas proposições devem ser confrontadas com os fatos e só têm validade se verificadas experimentalmente. Alia-se a isso a necessidade de 
explicitação metodológica para validar possibilidade de generalizações, critérios, repetição etc.

A necessidade de produzir conhecimentos sobre a realidade (de interesse prático) é essencial para o avanço do campo de Comunicação Organizacional. A observação empírica a partir da análise sistemática dos fatos poderá permitir uma intervenção qualificada.

O objeto da Comunicação é o fenômeno comunicacional da sociedade atual. Para Lopes (2003), o objeto é dinâmico e mutável. Extrapolar pesquisas meramente descritivas no campo da Comunicação é essencial no processo de construção teórica.

$\mathrm{O}$ aspecto central de qualquer pesquisa empírica consiste em observar a realidade. Da Viá e Dencker (2001, p.74) afirmam que "para que essa observação se processe de maneira científica e sistemática é necessário que o pesquisador defina de forma precisa o que deverá ser observado."

As autoras reforçam ainda que "no estudo qualitativo, a análise de dados segue um processo indutivo. Os pesquisadores não se preocupam em buscar evidências que comprovem as hipóteses. $\mathrm{O}$ fato, entretanto, de não existirem questões formuladas a priori não implica a inexistência de um quadro teórico" (DA VIÁ; DENCKER, 2001, p.186-187). Muitas são as pesquisas quantitativas que oferecem um falso rigor, amparado pela aparente inquestionabilidade dos números.

Dessa forma, a pesquisa qualitativa realizada com sete organizações de Goiás, tem no olhar do pesquisador seu principal instrumento, supondo, portanto, o contato direto com o ambiente que está sendo investigado.

Para esta pesquisa buscou-se uma variedade de tipos de serviços oferecidos pelas organizações, incluindo hotelaria, esporte, governo, instituições sem fins lucrativos, entre outras, com o objetivo de não serem trabalhadas somente organizações privadas.

O material obtido nessas investigações é rico em relato de pessoas, situações e acontecimentos, incluindo transcrições de entrevistas. A preocupação com o processo é tão importante quanto com o produto.

Podemos, então, caracterizar a pesquisa realizada sobre as assessorias de Comunicação no Estado de Goiás como empírica exploratória com a finalidade de formular um problema e esclarecer 
questões para desenvolver hipóteses, servindo de base para pesquisas futuras, numa abordagem qualitativa por meio de entrevistas. Apesar de estudos exploratórios não necessitarem de uma amostra comprovada estatisticamente, a pesquisa conduzida considerou a relevância da amostra de organizações de diversos segmentos.

No item seguinte destacamos o percurso da pesquisa, analisando cada passo e avaliando os principais resultados da pesquisa sobre as assessorias de Comunicação de organizações de Goiás. Assim, pautados no modelo de Lopes vamos tecendo a perspectiva metodológica da pesquisa e analisando os resultados da mesma.

\section{Assessorias de Comunicação e suas várias denominações - Reflexões sobre a Grande Goiânia}

“..creio ser tão impossível conhecer as partes sem conhecer o todo como conhecer o todo, sem conhecer particularmente as partes" (Pascal, Pensée, frase no 73).

É na dialética expressa por Pascal, citada na epígrafe acima, que introduzimos esta parte do artigo: uma proposta teórico-metodológica para abordagem qualitativa do trabalho com as assessorias de Comunicação em organizações no Estado de Goiás.

Toda problemática aqui abordada tem como espaço privilegiado de interrogação a prática da pesquisa, que se busca referenciar atividade fundamental na produção do conhecimento. Segundo Minayo (2000, p.10) "nem a teoria e nem a prática são isentas de interesses, de preconceito e de incursões subjetivas.” Bourdieu (1972, p.157) corrobora, afirmando que

[...] a teoria da prática que aparece como condição de uma ciência rigorosa das práticas, não é menos teórica; [...] qualquer investigador deve colocar em questão os pressupostos inerentes a sua qualidade de observador externo que tende a importar para o objeto os princípios de sua relação com a realidade.

Um dos objetivos deste estudo é enfocar as metodologias de pesquisa qualitativa nas organizações, entendidas como aquelas capazes de incorporar a questão do significado e da intenciona- 
lidade como inerentes às ações de Comunicação, às relações, e às estruturas sociais, sendo essas últimas tomadas tanto no seu advento quanto na sua transformação, como construções humanas significativas e principalmente como construções capazes de posicionar a organização no todo social. Segundo Lévy-Strauss (1975, p.215): "numa ciência onde o observador é da mesma natureza que o objeto, o observador é, ele mesmo, uma parte de sua observação”. Assim, este trabalho está carregado de valores adquiridos ao longo de mais de uma década de experiência dos pesquisadores à frente de Assessorias de Comunicação em instituições públicas e privadas. Por isso, a busca por um olhar imparcial passa pelas críticas inerentes à experiência, à vivência, até porque, toda busca pelo saber está baseada em pré-conhecimento, ou seja, ninguém coloca uma questão se nada sabe sobre a resposta. Se assim fosse, não haveria modo de se formular uma pergunta. Lênin, citado por Lukács (1967, p.235), completa, afirmando que "a marcha do real é filosoficamente mais verdadeira e mais profunda do que nossos pensamentos mais profundos".

Outro ponto a ser destacado é o da fase exploratória da pesquisa. Segundo Minayo (2000, p.89), "esta fase é tão importante que ela em si poderia ser considerada uma pesquisa exploratória” Consiste na etapa de escolha do objeto da investigação e do instrumento de coleta dos dados e da exploração de campo.

Quando realizamos uma pesquisa qualitativa podemos optar pelo roteiro de entrevista como instrumento de trabalho de campo. O roteiro de entrevista não é um questionário, ele contém poucas questões, o suficiente para orientar uma conversa, que podemos intitular de entrevista. É o facilitador e o norteador de uma relação comunicacional. Segundo Minayo (2000, p.99), é importante que cada questão que se levanta, faça parte do delineamento do objeto e que todas se encaixem para lhe dar forma e conteúdo; permita ampliar e aprofundar a Comunicação no lugar de cerceá-la; contribua para emergir a visão, os juízos e as relevâncias a respeito dos fatos e das relações que compõem o objeto, do ponto de vista dos interlocutores. O roteiro servirá como um guia e não como um obstáculo.

Quando pensamos na exploração de campo, a amostragem é ponto fundamental. Cabe considerar quem entrevistar, a quem 
observar e o que observar, o que discutir e com quem discutir, quais dados destacar como relevantes e quais informações podem ser desnecessárias. Numa pesquisa qualitativa o critério não é numérico, a amostragem qualitativa tem como principal objetivo os sujeitos sociais que detém os atributos que o pesquisador pretende conhecer.

\section{Um olhar sobre as Assessorias de Comunicação}

Para que fosse comprovada esta teoria na prática, no período de agosto e setembro de 2010, sete organizações de diferentes áreas de atuação, inseridas no Estado de Goiás, foram analisadas para que fosse compreendido o processo de desenvolvimento da Comunicação da organização com seus diferentes públicos.

Para isso foi criado um roteiro semiestruturado de entrevistas aplicado a vários funcionários dos Departamentos de Comunicação, com o objetivo de conhecer e analisar as organizações; suas formas de Comunicação e a relação com os diversos públicos; o tipo de linguagem, veículos e mensagens; o papel dos assessores de Comunicação frente às assessorias e a integração dos Relações Públicas.

O roteiro contemplava as seguintes questões: 1) histórico da organização; 2) organograma da organização e das Assessorias de Comunicação; 3) a missão, a visão e os valores da organização e das Assessorias de Comunicação; 4) as atividades diárias e as atividades esporádicas da Assessoria de Comunicação; 5) identificação da fonte de recursos para realização das atividades de Comunicação; 6) relacionamento com a imprensa; 7) publicações de responsabilidade da Assessoria de Comunicação; 8) realização de eventos - objetivos e periodicidade; 9) Comunicação interna e externa; 10) veículos de Comunicação adotados; 11) produção de mapas de mídia; 12) públicos que interagem com as organizações.

Foram selecionadas organizações das áreas de Hotelaria Castro’s Park Hotel; Esporte - Goiás Esporte Clube; Organizações ligadas ao Sistema "S", Sebrae (Serviço Brasileiro de Apoio à Micro Empresas) e Senac (Serviço Nacional do Comércio); Associação sem fins lucrativos - Apae (Associação de pais e amigos do excepcional); e organizações do primeiro e segundo setor, através da Assessoria 
de Comunicação do Governo do Estado de Goiás e da Empresa Porto Seco Centro Oeste.

Parte dos profissionais que estão à frente das Assessorias não são formados em Comunicação social e tiveram dificuldades, inclusive, de responder às perguntas da entrevista. Dos profissionais que afirmaram não ser formados em Comunicação, alguns tiveram forte tendência a justificar que o trabalho de liderança de uma equipe se firma na administração e não na especialização do líder na área que chefia. Neste sentido, encontramos um reforço à metodologia adotada, pois com o processo de entrevista os assessores de Comunicação tiveram uma reação de explicação do fato de não serem formados em Comunicação Social, dado este que num questionário fechado se perderia. Portanto, a abordagem qualitativa mostrou-se mais adequada à pesquisa conduzida que extrapolou a própria investigação da área de formação de cada um deles.

Todas as organizações possuem organograma constituído, mas nenhuma possui organograma da Assessoria de Comunicação. Apesar de todas elas conseguirem explicar verbalmente as atividades de cada um dos integrantes da Assessoria, não há uma descrição formal das atividades, impressa e discutida formalmente pelos profissionais das Assessorias.

Neste momento da pesquisa, ficou claro que os entrevistados buscaram sempre justificar a ausência do organograma da assessoria de Comunicação, afirmando que tinham plena consciência de sua importância, mas que a sua inexistência era trabalhada por outras formas de relacionamento com os integrantes da equipe. Não houve nenhum entrevistado que assumisse não achar importante a descrição formal das atividades, embora nenhum tenha se prontificado a fazê-la após a entrevista.

Algumas organizações desenvolvem suas atividades de Comunicação a partir da Assessoria de Marketing ou Assessoria de Imprensa, não necessariamente porque dão ênfase às ações de Imprensa ou de Marketing, mas por total desconhecimento das diferenças entre as três assessorias (Marketing, Imprensa, Comunicação). Neste caso, as nomenclaturas são definidas a partir de uma escolha não necessariamente justificada pelas atividades, mas pela predileção de quem está no comando. 
A partir desse questionamento, percebe-se que as nomenclaturas podem ser escolhidas por uma necessidade de justificativa social, muito mais do que pela necessidade dos serviços executados pelas assessorias de Comunicação.

A maioria trabalha com eventos, mas poucas possuem a consciência da importância do evento como ferramenta de Comunicação e desperdiçam a chance de promoverem um acontecimento brilhante, capaz de transmitir uma mensagem aos seus diferentes públicos.

Raras são as organizações que produzem relatórios trans e pós eventos, tampouco registro das ocorrências em tais trabalhos. A confusão entre o que é evento e o que é festa também é nítida para algumas organizações que se justificam como sendo uma determinação superior da própria organização.

Segundo Giácomo (1993), como processo de Comunicação e linguagem, os eventos organizacionais precisam respeitar a realidade de cada público, e de suas próprias regras de sintaxe, porque será sempre parte de uma atividade de Comunicação. Para ela, o evento é capaz de levar uma mensagem em condições propícias, no momento certo, analisando características como luz, som e ambiente adequados. Ao final de cada evento, cada participante deveria levar consigo um resíduo de mensagem e não somente a lembrança de uma festa.

Para algumas organizações, a atividade de assessoria de imprensa se sobrepõe a qualquer outra atividade de Comunicação. Para os assessores pesquisados, "o que não está na mídia não existe" e os diretores e proprietários das organizações solicitam diariamente a colocação de suas atividades nos meios de Comunicação de massa.

Nenhuma assessoria apresentou um organograma composto por profissionais de todas as áreas de Comunicação social, ou seja, jornalistas, Relações Públicas, publicitários. Apesar de o Governo do Estado ter uma quantidade grande de funcionários que trabalham nas atividades de Comunicação, não há um departamento que agregue todos os profissionais, mas sim vários departamentos que executam tarefas diversas, trabalhando muito mais numa divisão de trabalhos do que numa soma de esforços para uma Comunicação integrada. 
Mesmo quando a pesquisa foi aplicada em uma organização de Grande Porte ${ }^{1}$ como a Porto Seco Centro Oeste, o que se verifica é a existência de uma Assessoria de Comunicação muito precária, com apenas uma profissional de Relações Públicas e um estagiário também de Relações Públicas.

A maioria absoluta dos entrevistados mostrou muito receio em externar críticas às suas organizações no tocante à necessidade de ampliação, reformulação e maior apoio aos trabalhos das Assessorias de Comunicação.

Os entrevistados citaram verbalmente a missão, a visão e os valores das organizações, mas poucos conseguiram apresentar oficialmente essas informações. Nenhum deles conseguiu explicar a forma como cada um desses itens é construído dentro das organizações. Claramente pudemos perceber a criação de alguns desses itens sendo feitos no momento da entrevista.

Nenhuma Assessoria de Comunicação possui missão, visão e valores dos Departamentos de Comunicação e a maioria demonstrou sequer ter consciência da importância destas definições para as Assessorias. Alguns chegaram a citar a visão, missão e valores da Organização como sendo os mesmos das Assessorias.

Todos afirmaram ter consciência da importância da Assessoria de Imprensa e da importância do relacionamento de sua organização com os meios de Comunicação de massa do Estado de Goiás.

Segundo Mafei (2004), um assessor para estabelecer e executar práticas que levem à veiculação de informações precisas, deve dominar as técnicas de produção jornalística, com todas as suas interfaces, respeitando as características de cada veículo de Comunicação. No caso das Assessorias de Comunicação pesquisadas no estado de Goiás, isso não é uma regra.

As organizações ligadas ao sistema "S" possuem consciência da definição e do trabalho específico a ser realizado com cada um dos públicos que com elas interage, mas instituições como o Goiás

\footnotetext{
${ }^{1}$ O Porto Seco de Anápolis - Goiás é uma das empresas que mais atrai investimentos para a região. Anualmente, mais de US\$ 500 milhões em mercadorias passam pelos seus terminais. O Porto Seco movimenta 22 mil toneladas de carga ao mês, representando $40 \%$ da carga brasileira transportada pelo Trem Expresso da Ferrovia Centro-Atlântica.
} 
Esporte Clube não. A formação da opinião pública para algumas organizações é feita somente a partir das informações veiculadas nos meios de Comunicação de massa, por total desconhecimento do que é formação de opinião pública, a importância dos líderes de opinião para reafirmarem a própria existência das organizações e a necessidade de distinção dos públicos que pertencem às organizações. O sentido de massa é muito mais claro para grande parte dos assessores do que o sentido de valorização, adequação, identificação e necessidade de trabalho com públicos distintos.

É comum encontrarmos na teoria a necessidade de o Departamento de Comunicação estar ligado diretamente à Administração Superior da organização, assim, ele estará a par das preocupações da empresa e dos seus pontos de interesse, pois a atuação da assessoria reduz-se na proporção direta de seu pouco diálogo com a direção. Nem todas as assessorias pesquisadas possuem uma participação direta nas discussões do alto escalão das organizações.

As atividades diárias das organizações resumem-se à produção de clipping, atualização do site ou portal, atendimento à imprensa. Há organizações que adotaram a Internet como ferramenta de Comunicação interna e produzem newsletter ou Jornal Eletrônico. Contudo, o uso da Internet para o trabalho de Relações Públicas ainda é limitado. Normalmente a Internet é utilizada para desenvolvimento de atividades de Jornalismo.

Questionados sobre a possibilidade de uma Comunicação via Internet para minimizar efeitos negativos em uma possível situação de crise, os profissionais se mostraram inseguros e descrentes da eficácia da mídia para o problema. Essa posição demonstra que parte dos assessores pesquisados não possuem conhecimento de que uma visão tática e estratégica dos usos e das aplicações das técnicas de Relações Públicas nos diferentes serviços da Internet são muito eficientes e os resultados obtidos nas ações e nos programas que visem a informar e a influenciar públicos de interesse de empresas e instituições são relevantes e efetivos.

Considerando-se que a abordagem dos principais serviços que a Internet possibilita, como listas de discussões, chats, redes sociais, entre outros, oferece oportunidades para o trabalho de Relações Públicas e a identificação dos públicos que interagem com uma organização. 
As instituições pesquisadas demonstraram conhecimento sobre a importância do trabalho social de uma organização para a formação positiva da opinião pública, mas nem todas elas possuem um programa de responsabilidade social permanente. Algumas realizam atividades esporádicas, desconhecendo o conceito de continuidade, tão importante para o reforço da marca e da imagem da organização para seus diversos públicos.

Segundo Tuzzo (2005), "Em nenhum outro momento na história das organizações se falou tanto sobre a responsabilidade social de empresas de todos os portes e de qualquer área de atuação”. O trabalho social é importante no sentido de construir uma imagem positiva junto aos diferentes públicos de uma organização; até porque, num país como o Brasil, em que o trabalho de assistência à sociedade, por parte de lideranças governamentais, deixa muitas vezes de ser cumprido, o papel de empresas privadas preenche lacunas fundamentais de sobrevivência de toda a comunidade.

Ao não darem o devido valor às questões de responsabilidade social, as empresas perdem a chance de produção de notícias positivas e reforço da marca, pois uma atitude mais humanista das organizações trabalha na sua construção da imagem. Mais que isso, o trabalho social fez surgir, a partir da década de 80 , um novo enfoque das Relações Públicas a partir de um trabalho comunitário, mostrando que o trabalho de Relações Públicas não se restringe às empresas e ao governo, mas se estende a qualquer tipo de organização e movimentos sociais.

Realizada a apresentação e análise dos resultados da pesquisa e estabelecida a trajetória metodológica, pode-se perceber a relevância da explicitação metodológica no âmbito do campo da Comunicação. Para reforçar essa ideia, recorremos a Lopes, que sustenta que:

a reflexão metodológica não só é importante como necessária para criar uma atitude consciente e crítica por parte do investigador quanto às operações científicas que realiza na investigação e quanto ao questionamento constante a que deve submeter os métodos ante as exigências que lhe impõe a realidade. (LOPES, 2003, p.92)

Fica clara a importância da pesquisa empírica para a busca de informações sobre as assessorias de Comunicação no Estado de 
Goiás para tentarmos construir um universo de informação sobre a atuação dos profissionais de Comunicação, sua relação com as organizações e com os meios de Comunicação.

\section{À guisa de conclusão}

Este trabalho legitima a necessidade da pesquisa empírica no âmbito das Relações Públicas e da Comunicação Organizacional, destacando a sua importância na construção do discurso científico.

As opções metodológicas feitas de forma consciente implicam necessariamente na reflexão da prática da metodologia. Lopes (2003) salienta que as opções metodológicas são normalmente tomadas com um baixo grau de consciência por parte do investigador. Nas pesquisas em Comunicação ela afirma que esse fato se expressa por uma quase ausência de explicitação da estratégia metodológica que sustenta a pesquisa. Essa realidade revela a falta de um discurso sobre o método.

$\mathrm{Na}$ pesquisa em análise há essa explicitação da estratégia metodológica, ou seja, os pesquisadores tiveram esse grau de consciência que pode ser observado a partir da definição do roteiro de entrevista, da seleção das organizações a serem pesquisadas, no critério de seleção dos profissionais que seriam entrevistados e, principalmente, na relação da pesquisa empírica e teórica. Entendemos ser esse olhar vigilante do pesquisador necessário para garantir a apreensão do discurso científico.

A instância da técnica é determinante para a emergência do campo e sua institucionalização. No contexto da Comunicação Organizacional e das Relações Públicas a instância da técnica tem feito emergir a necessidade de aprofundamento teórico e de desenvolvimento de pesquisas empíricas que comprovem tais teorias.

A Comunicação Organizacional e as Relações Públicas, como áreas em plena expansão, constituem-se basicamente de estudos recentes. A inserção dessas áreas em linhas de pesquisa nos programas de pós-graduação em Comunicação é um passo na consolidação desses estudos. A importância da constituição do aparato teórico e metodológico torna-se fundamental para a pesquisa empírica. Portanto, a proposta de refletir esse fazer pesquisa em Comuni- 
cação Organizacional e Relações Públicas, permite-nos analisar a trajetória teórica e metodológica que tem suportado a construção histórica desse objeto.

Com a análise dos resultados e da metodologia da pesquisa empírica em questão, espera-se uma reflexão que de alguma forma aponte rumos que entendemos serem essenciais na produção do conhecimento científico no âmbito da Comunicação Organizacional e das Relações Públicas.

\section{REFERÊNCIAS}

BEILlEROT, J. A sociedade pedagógica. Porto: Rés, 1985.

BOURDIEU, Pierre. Ésquisse d'une théorie de la pratique. Paris: Librairie Droz, 1972.

BRAGA, J.L. Constituição do campo da Comunicação. In: FAUSTO NETO, A. et.ali. (org.) Campo da comunicação: caracterização, problematizações e perspectivas. João Pessoa: Editora Universitária/UFPB, 2001.

BRAGA, J.L.; CALAZANS, M.R.Z. Comunicação e educação: questões delicadas na interface. São Paulo: Hacker, 2001.

DA VIÁ, S. e DENCKER, A. Pesquisa empírica em ciências humanas (com ênfase em Comunicação). São Paulo: Futura, 2001.

GIÁCOMO, Cristina. Tudo acaba em festa. São Paulo: Scritta Editorial, 1993.

LÉVY-STRAUSS. Aula inaugural: desvendando máscaras sociais. Rio de Janeiro: Editora Francisco Alves, 1975.

LOPES, M. I. V. de. Pesquisa em comunicação. 7.ed. São Paulo: Loyola, 2003.

LUKÁCS, G. Existencialismo ou marxismo? São Paulo: Editora Senzala, 1967.

MAFEI, Maristela. Como se relacionar com a imprensa - como se relacionar com a mídia. São Paulo: Contexto, 2004.

MARTINO, L.C. Elementos para uma epistemologia da Comunicação. In: FAUSTO NETO, A. et.ali. (org.) Campo da comunicação: caracterização, problematizações e perspectivas. João Pessoa: Editora Universitária/UFPB, 2001. 
. Interdisciplinaridade e objeto de estudo da Comunicação. In: FAUSTO NETO, A. et.ali. (org.) Campo da comunicação: caracterização, problematizações e perspectivas. João Pessoa: Editora Universitária/UFPB, 2001.

MASETTO, M.T. Docência na universidade. Campinas: Papirus, 1998.

MINAYO, Maria Cecília de Souza. O desafio do conhecimento: pesquisa qualitativa em saúde. São Paulo: Hucitec; Rio de Janeiro: Abrasco, 2000.

TUZZO, Simone Antoniaci. Deslumbramento coletivo: opinião pública, mídia e universidade. São Paulo: Annablume, 2005.

Recebido em: 23/06/2010 Aceito em: 15/02/2011 